\title{
PRIVATE-LABEL SHARE DURING THE CURRENT ECONOMIC SLOWDOWN: INVESTIGATION FROM THE CZECH, SLOVAK, HUNGARIAN AND POLISH MARKETS
}

Týra, K., Karlíček, M.

This paper investigates whether the current economic slowdown in four CEE countries was accompanied by strong growth of private-label share as theory suggests. Unexpectedly, based on the data of Nielsen Retail Measurement Service, we prove that the private-label share grew relatively slowly, although all four countries had a large potential for growth of this share. We demonstrate that the key reason behind this development was probably the massive in-store promotions that were decreasing the price gap between private labels and branded products. The managerial implications of these findings for both manufacturers and retailers within the region are discussed.

JEL Classification: M31

\section{Introduction}

The popularity of private labels (or store brands) has been steadily rising over the past decades in the developed world (Lamey et al., 2007). In some European countries, such as Switzerland or the United Kingdom, the privatelabel share has even exceeded $40 \%$ recently (see figure 1). However, in CEE countries, the private-label share is still relatively low. In 2010, the share of private labels in Slovakia and Hungary reached $20.1 \%$, in the Czech Republic $17.3 \%$ and in Poland $16.4 \%$.

All four CEE countries experienced very fast and dynamic development in the retail structure over the last two decades. The importance of "Traditional Trade" (stores with a selling area of less than 400sqm) declined whereas the "Modern Trade" (hypermarkets, supermarkets and discounters) grew significantly. During the last few years, the share of "Modern Trade" has become relatively stabilized in these countries. It counts for approximately $78 \%$ in the Czech Republic, $68 \%$ in the Slovak Republic, $62 \%$ in Hungary and 58\% in Poland (Nielsen Retail Audit). Therefore the potential for growth of private-label share is large in all four markets. Another reason why private-label share should be increasing in all the markets in question is the home countries
Figure 1: Value Share of Private Labels in European Countries (in 2010)

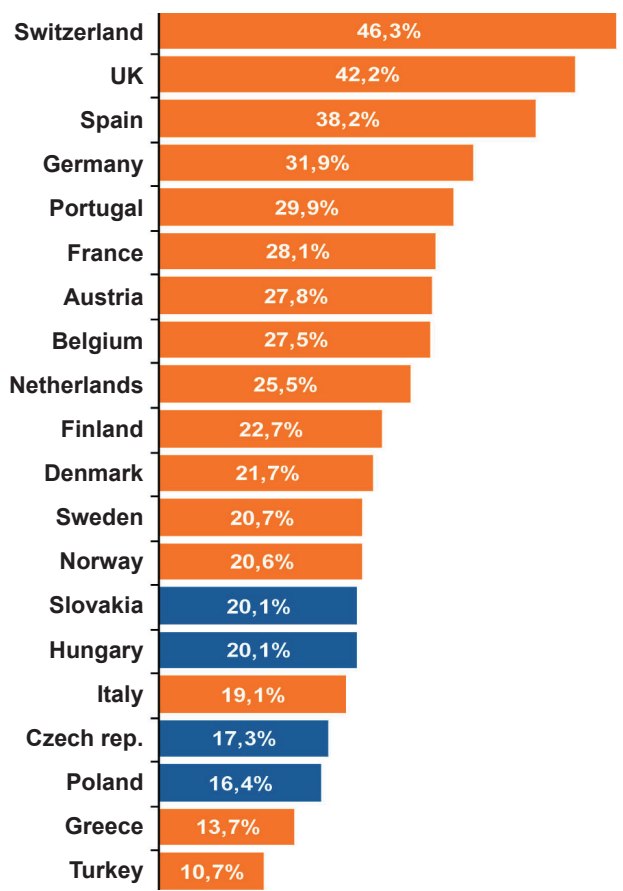

Source: Nielsen Retail Audit (all available FMCG categories) 
of major retailers that are active in the region. Most of these retailers have their headquarters in the United Kingdom, Germany, Austria or France, i.e. in countries that have very good experience with private labels.

\section{The Cyclical Dependence of Private-Label Share}

The success of private labels has been attributed to many different factors. These are, among others, an ongoing shift of the manufacturers from advertising to sales promotions, the growing concentration of the retail sector, gradual improvement in the quality of private labels or the increasing efforts that retailers put in the private labels (Lamey et al., 2007). However, many authors link privatelabel success primarily with economic factors.

The existing research suggests that private-label share depends, in a huge way, on business cycles. Consumers become more concerned with price when their income lowers (Wakefield and Inman, 1993). During economic slowdowns they therefore switch to private labels because private labels are, on average, about $40 \%$ cheaper than manufacturers' brands (Dhar and Hoch, 1997).

For example, Quelch and Harding (1996) mention that during the 1981 and 1982 economic recession in the United States the private-label share increased significantly. Similarly, Lamey et al. $(2007,2012)$ proved, on data from the United States and Europe, that during economic downturns private-label share increased and shrank during good economic times.

However, these researchers also found certain asymmetries in this counter-cyclical development of private-label share. According to their research, consumers switch to private labels more extensively during economic downturns than they switch back to manufacturers' brand in a subsequent economic upturn. Furthermore, the consumers' switch to private labels is faster than the subsequent switch to manufacturers' brands. Finally, some consumers keep buying private labels even when the economic downturn is already gone because they experience that real private-label quality exceeds their past perceptions (as the perceived quality of private labels is typically lower than their real quality) and because purchasing private labels become habitual for them during the economic downturn.

It has been suggested that the counter-cyclical development of private-label share is further strengthened by both the retailers and the manufacturers. In general, the retailers support their private-label programs more intensively during economic downturns whereas they cut these programs back during economic upturns, which further supports the cyclical sensitivity of private-label share (Lamey et al., 2012). Additionally, during economic downturns the manufacturers cut their marketing expenses, i.e. they cut promotions, advertising costs and innovations (Lamey et al., 2007, 2012). These adjustments again support the counter-cyclical development of private-label share.

\section{The Economic Slowdown in the CEE Markets}

Since 2009 the four CEE countries have faced different market development than in the past. With the exception of Poland, the overall economies were in economic downturn or slowdown (see figure 2).

Figure 2: GDP Development in the Czech Republic, Hungary, Poland and Slovakia

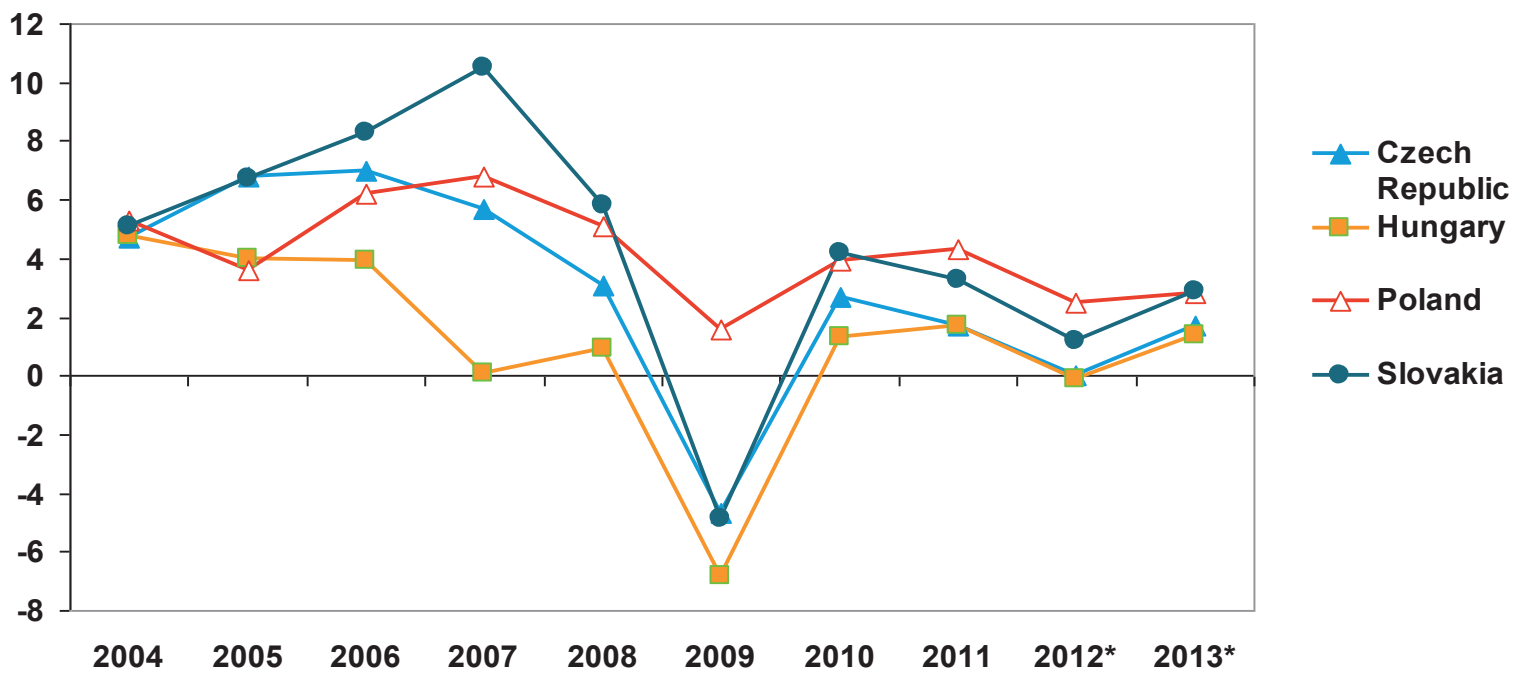

Source: Eurostat 
Figure 3: FMCG Development Drivers in the Czech Republic, Hungary, Poland and Slovakia

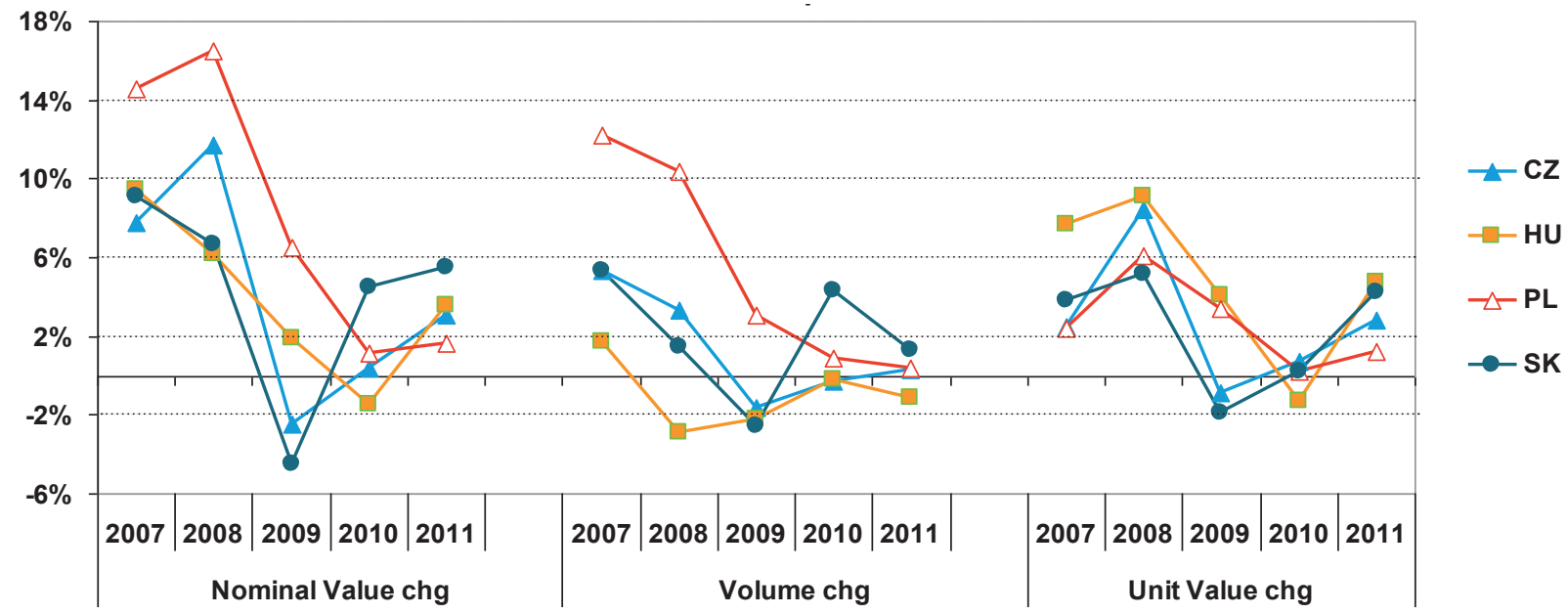

Source: Nielsen Retail Audit (all monitored FMCG categories)

Also, within the FMCG industry, it was no longer sufficient for the manufacturers and retailers to keep the trend of the category or market to generate growth (see figure 3). From all four countries, only Poland remained positive in value development, but also dropped from rocket growth in 2007 and 2008 to almost stagnation in the past two years.

Czech and Slovak FMCG markets faced the biggest decline during 2009 driven by volume declines which were not compensated by unit value growth. The situation in Slovakia was also significantly influenced by introduction of the Euro in 2009, which (supported by the current disadvantageous exchange rate) lead to cross-country shopping. This phenomenon deepened the decline, especially in the border area and in the bigger formats of stores. On the other hand, the very deep decline in 2009 helped Slovakia to have more positive development the year after. In Hungary, the volume sales have been declining over the long-term and the positive value growth was pulled only by price level (also, in Hungary, inflation reached the highest level from this micro-region).

Under these circumstances, many experts expected strong growth of private-label share within the CEE region. However, has the development of private-label share been really as dynamic as both the theory and intuition suggest? In this paper, we will try to validate or reject this hypothesis.

\section{Research Questions and Methodology}

Our research question is whether the private-label share in the four CEE countries developed counter-cyclically during the current economic slowdown, i.e. whether the private-label share in those countries increased significantly within the timeframe, as the theory suggests.

We used data of Nielsen Retail Measurement Service (Nielsen RMS), which measures the market development and details on sales generated in retail stores. Nielsen RMS is focused on reporting FMCG categories in the market channels that are important in the respective country, covering usually food \& mixed stores, drug stores, tobacco stores, petrol stations and special stores for categories where relevant (as sweet shops, delicatessen, pharmacies etc.). The most important facts measured by Nielsen RMS are sales in value, volume $(\mathrm{kg} / \mathrm{l})$, items, prices and distributions for total category including split to particular segments and items. Key sources of the data are cooperating chains, providing scanning data (exact sales that goes through cashiers) and manual audit.

\section{Findings}

When we analyzed the development of private-label share in the CEE countries within the last three years; we found stagnation or only a very slow increase (up to $1 \mathrm{pp}$ per year). This development was opposite of the expectations, theoretical assumptions and experience from Western countries (see figure 4). The only exception was Poland where private-label share grew faster, supported by the concentration and increasing importance of "Modern Trade". 
Figure 4: Value Share of Private Labels in the Selected Basket

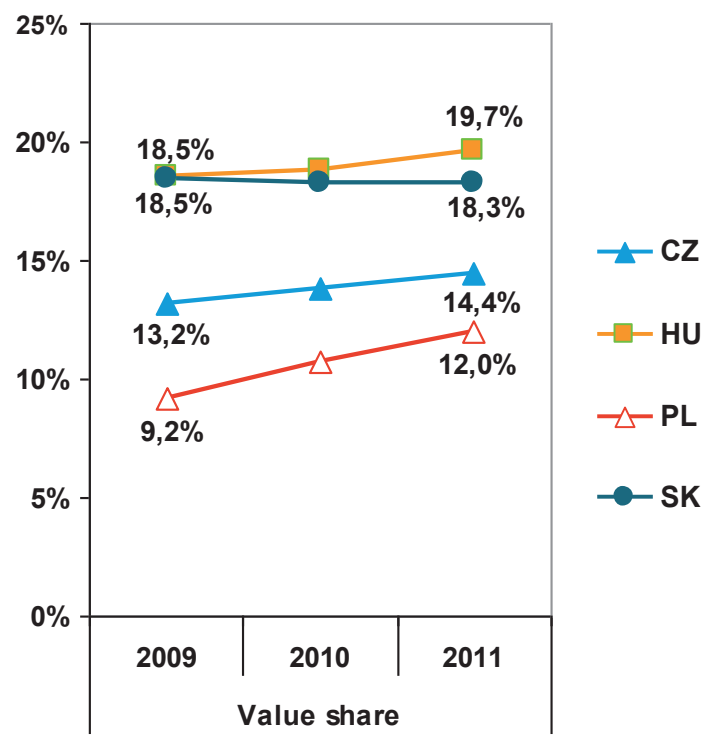

Source: Nielsen Retail Audit ${ }^{1}$

To better understand the reasons behind this unexpected development, we further analyzed the price index of private labels to branded products. We found that this price index increased during the last three years in all four countries (see figure 5). This means that the price gap between the private labels and branded products decreased.

This tendency could have two reasons: It could be that the retailers launched new premium lines of private labels as is typical in Western countries (i.e. that the relative prices of private labels increased), or that the relative prices of branded products decreased.

To answer this question, we compared the development of price levels within private labels and within branded products. In the top food and drug categories we found faster growth of prices within private labels than within branded products. For example, in the Czech Republic, the price level of private labels in this basket grew by $9.7 \%$ while the price level of branded products grew only by $5.5 \%$. In the Slovak Republic it was $6.8 \%$ vs. $4.6 \%$. These findings suggest that the increase of the price index could have been caused primarily by a relative decrease of branded products' prices.

1 Selected basket of the following categories: Beer, Chocolate Confectionery, Cheese, Butters \& Margarines, Sweet Biscuits \& Wafers, Waters, Yogurts, Coffee, Milk, Wine, Soft Drinks, Juices, Vodka, Pet Food, Detergents, Toilet Paper, Diapers, Baby Food, Deodorants, Face Care, Toothpastes, Sanitary Protection, Shower Gels, Shampoo, Household Cleaners.
Figure 5: Price Index of Private Labels to Branded Products in the Selected Basket

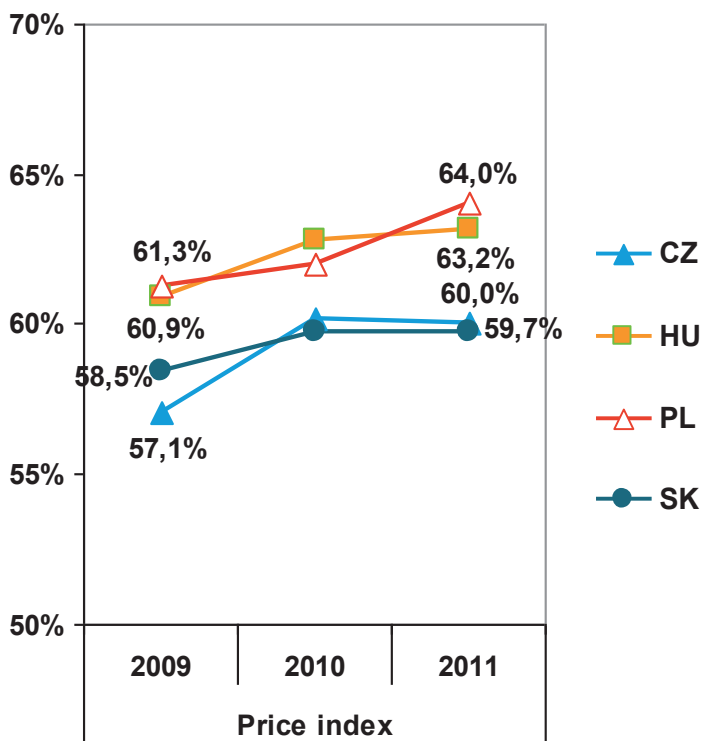

Source: Nielsen Retail Audit

We hypothesized that the main reason behind the diminished price gap between the private labels and branded products was in-store promotions like temporary price reductions or special promo packs (overfills, bonus or banded packs). These tools represent an extremely powerful tool, which helps manufacturers fighting private labels during economic slowdown (Lamey et al., 2012).

For promotional analysis, Nielsen ScanTrack service was used; it is based on weekly scanning data from cooperating chains and it differentiates promotional and non-promotional sales. The following are considered promotion: temporary price reductions, leaflets and promotional packs.

When we compared the basket of the most important food and drug categories across the four countries, we found that with the exception of Poland, almost half of the sales was done with promotional support during the last three years (see figure 6). Moreover, the promotional support was growing during the last three years (again with the exception of Poland).

Therefore it seems that the main reason why private labels did not strengthen their position significantly in the four countries during the economic slowdown was most probably promotional pressure. It can be expected that this pressure was slowing down the relative price level increase of branded products which may have resulted in lower demand for private labels. 
Figure 6: Percentage of Sales Supported by Promotions

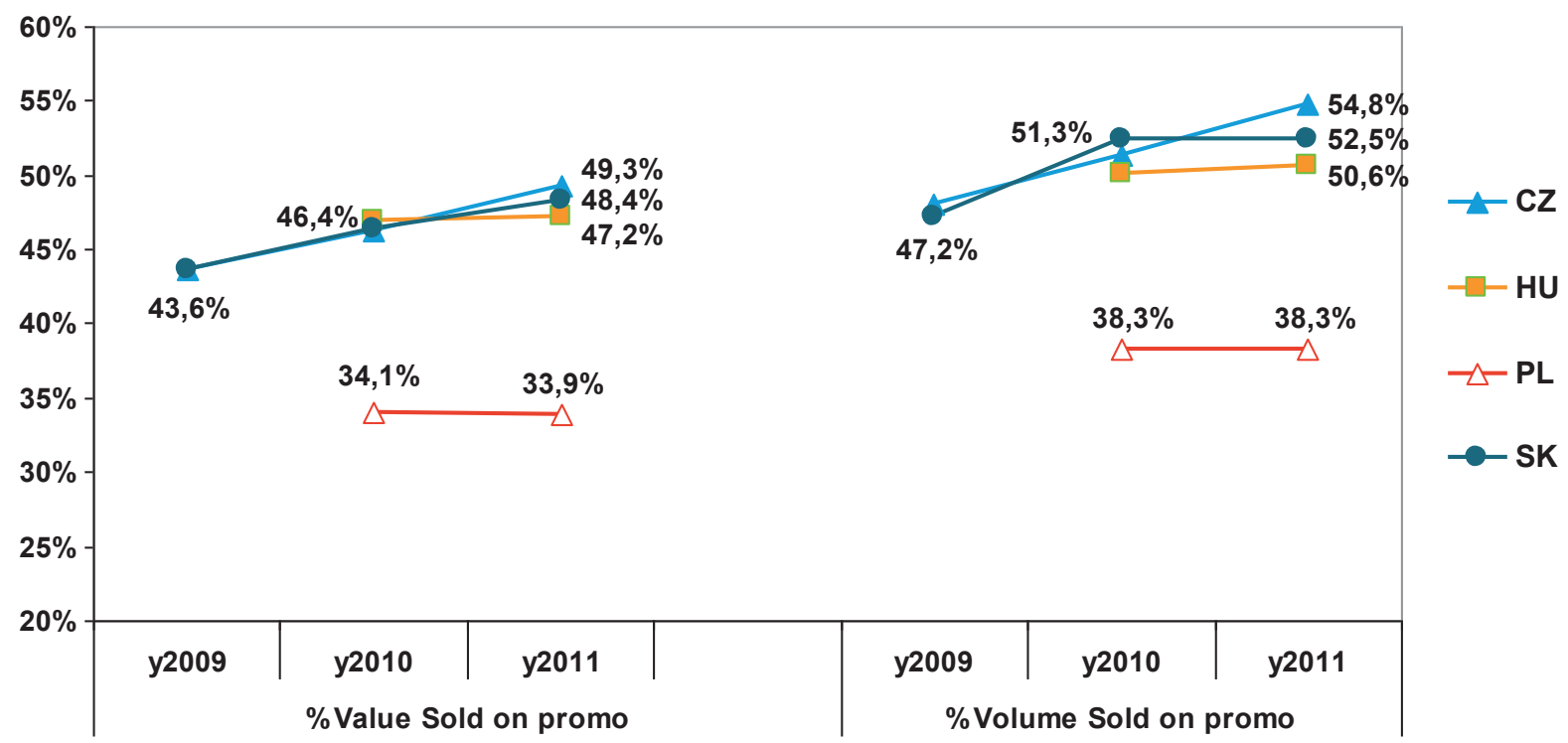

Source: Nielsen Retail Audit - ScanTrack

\section{Conclusion}

Private labels are often presented as a threat for manufacturers' brands, especially during an economic downturn. However, it seems that on some markets, the situation is not as alarming as on other markets. In the Czech Republic, Slovakia, Poland and Hungary the private-label growth was slow during the economic slowdown, despite the high potential private labels had on these four markets.

Contrary to current research (e.g. Lamey et al., 2012), the intensity of manufacturer brands' promotions increased in CEE countries during the economic slowdown. It seems that the manufacturers were involved within a price-promotion spiral which was decreasing the relative prices of branded products to private labels. This tendency was preventing the private-label share to increase. However, further research is necessary to support these findings conclusively.

\section{Managerial Implications}

Our paper uncovered that manufacturers in the four CEE countries are most probably involved within a pricepromotion spiral, which prevents private-label share from increasing. Such development may seem positive

2 Selected basket of the following categories: Beer, Chocolate Confectionery, Butters \& Margarines, Waters, Coffee, Soft Drinks, Juices, Detergents, Toilet Paper, Deodorants, Toothpastes, Shower Gels, Shampoo. for the manufacturers. However, at the same time, it is connected with high risks.

Though the high intensity of promotions helps fight private labels and it significantly boost sales (the Nielsen data show that it is not an exception that during one 2-week promotion the sales overachieve standard non-promo sales done in six months), this strategy may be myopic. From the perspective of one year, it can support the results and increase the volumes sold. However, in the situation when the total market is flat, next year it is necessary to repeat the same aggressive promotion to keep the sales on the same level as a year ago. Moreover, frequent price promotions raise price sensitivity of consumers and encourage brand switching (Quelch and Harding, 1996).

Most manufacturers are not satisfied with the current dependence on sales promotions; however, they are not able to stop the price-promotion spiral. Manufacturers (and their stakeholders) who try to step off the moving train have to be prepared for a drop in sales. However, from the longer perspective, stepping off can create a potential for increase in profitability.

In the near future, promotions will probably be growing within the four CEE countries. The winners will be those manufacturers who will be able to work effectively with the promotional tools and who will have a clear picture about the promotional tools' profitability. Econometric analyses on Nielsen sales data in the CEE region prove large differences in the effectiveness of promotional 
tools not only among categories but also within one category. What works for one brand may not work for another. There are even differences on an item level - for example, a big package needs different support than a smaller one etc. Furthermore, the manufacturers' growth has to be supported by organic elements (innovations, loyalty building, optimization of distribution etc.) not only sales promotion.

Our findings have important implications also for retailers in CEE countries. Retailers should change their current approach towards private labels. If they continue to use private labels only as "price fighters" without other differentiation and connection with their brand, they will compete directly with branded products and their promotions. This will further support the consumers' desire to buy at the lowest price possible.

In the countries with a high share of private labels, the difference between price level of private labels and branded products is the lowest. Both Switzerland and United Kingdom have the price index of private labels to average category price close to $90 \%$ (Nielsen Retail Audit). However, the same is true also in the CEE region. When we compare the categories across the four countries and analyze those where private labels are already strong (above $20 \%$ of value share), we can see that these categories are having the price level of private labels very close to branded products (a majority of them with a price index of private labels to branded products between 70 and 95\%). In these categories (Juices, Milk, Cheese, Toilet Paper, Diapers, Pet Food or Sweet Biscuits), private labels do not have a significant price advantage, but the manufacturers of branded products were not successful in persuading consumers to be loyal to their brands.

Based on this experience, we can expect that the strategy of higher quality private labels (that are still cheaper than branded products but not necessarily significantly cheaper) enables to build loyalty to the retailer and helps especially in the time of an economic downturn. This approach would not support further growth of a price war between the cheapest private labels versus the highest price discount on branded products.

\section{References}

Dhar, S. K., Hoch, S. J. (1997). Why Store Brand Penetration Varies by Retailer. Marketing Science, 16(3): 208-227.

Lamey, L., Deleersnyder, B., Dekimpe, M. G., Steenkamp, J., E., M. (2007). How Business Cycle Contribute to PrivateLabel Success: Evidence from the United States and Europe. Journal of Marketing, 71 (January): 1-15.

Lamey, L., Deleersnyder, B., Steenkamp, J., E., M., Dekimpe, M. G. (2012). The Effect of Business-Cycle Fluctuations on Private-Label Share: What Has Marketing Conduct Got to Do with It? Journal of Marketing, 76 (January): 1-19.

Quelch, J. A., Harding, D. (1996). Brands Versus Private Labels: Fighting to Win. Harvard Business Review, 37 (Winter): 99-109.

Wakefield, K. L., Inman, I. J. (1993). Who Are the Price Vigilantes? An Investigation of Differentiating Characteristics Influencing Price Information Processing. Journal of Retailing, 69 (2): 216-233.

Authors
Ing. Karel Týra
Client Service Director, Nielsen
Hvězdova 1716/2b, Praha 4, 14078
karel.tyra@nielsen.com
Ing. Miroslav Karlíček, Ph.D.
Head of Marketing Department
Faculty of Business Administration
University of Economics, Prague
nám. W. Churchilla 4, Praha 3, 13067
miroslav.karlicek@vse.cz

This paper has been created with the financial support of the Internal Grant Agency of the University of Economics, Prague (research project $\mathrm{mF} / 13 / 2012$ ). 